\title{
Thresholds for dynamic visual movement
}

\author{
WILLIAM W. AGRESTI \\ University of Michigan-Dearborn, Dearborn, Michigan 48128 \\ and \\ MARK S. MAYZNER \\ Loyola University, Chicago, Illinois 60626
}

\begin{abstract}
The present study, employing a computer-based cathode-ray tube (CRT) display system, seeks to extend earlier findings on "dynamic visual movement." A methodology is developed that attempts to assess thresholds for various phases of "subjective visual experience," and quantitative estimates of such thresholds are examined.
\end{abstract}

Dynamic visual movement refers to a particular apparent movement phenomenon that was first reported in 1970 (Mayzner \& Tresselt, 1970). The effect is produced by using a computer-driven cathode-ray tube (CRT) display system to generate characters on the screen in a complex spatiotemporal arrangement. The original study used 20 letter Os positioned next to each other to form a line at the center of the display surface. The timing and sequencing of the individual letter presentations was such that it produced an unexpected visual experience. Subjects reported seeing four letter $O s$ in smooth motion across the screen.

The present experiment was designed to explore that "display timing" that appears critical to the production of dynamic visual movement. The objective was to assess three thresholds in the subjective experience of individuals who are presented with complex visual stimuli, in which the display consists of 36 letter Xs that, with the proper timing, can produce dynamic visual movement. However, the timing is varied by the experimenter so that four subjective visual experiences can be distinguished: (1) Pure sequentiality. The presentation time is so long $(500 \mathrm{msec})$ that each letter $\mathrm{X}$ appears in sequence. (2) Transient phase. Here the individual presentation times of the letters are less than those above, so that more than one $\mathrm{X}$ appears to be present on the screen at any one instant but dynamic visual movement does not occur. (3) Dynamic visual movement. A number of Xs appear to be in motion across the screen, the number depending on the ordering used. (4) Simultaneity. All 36 Xs appear to be present on the screen simultaneously.

It is important to note that these four distinct subjective visual experiences arise from the same display: Only the presentation times of the individual letters change. Only one letter $\mathrm{X}$ is being displayed at any

This research was supported in part by National Science Foundation Grants BG-22785 and BNS 75-09800 A 02 to the second author. given time. However, because of the very short presentation times (as low as $1 \mathrm{msec}$ ) attainable with the computer-driven display, the subjective experience is not always that of sequential presentation of the letters.

The first phase above is labeled pure sequentiality to indicate that the subjective experience is in complete agreement with the actual sequential method of generating presentations. The individual presentation times at this phase are long enough so that the letters, which are generated one at a time, also appear to have been generated that way. In the other phases, such is not the case. As the presentation times grow successively shorter, Phases 2, 3, and 4 are reached in turn.

The experiment seeks to identify those critical presentation times when the subjective visual experience changes from one phase to another. The thresholds are labeled $\mathrm{A}, \mathrm{B}$, and $\mathrm{C}$ for identification purposes as follows: (1) Pure sequentiality, A, (2) transient phase, B, (3) dynamic visual movement, C, (4) simultaneity. Thresholds $\mathrm{B}$ and $\mathrm{C}$ are of special interest, providing upper and lower bounds on the dynamic visual movement phenomenon.

Underlying this study is the continuing interest in the operation of the human visual system. It is intended that, by subjecting that system to such complex stimuli, more evidence will be obtained on the sophisticated processing of the information into various perceptual organizations.

\section{METHOD}

The five subjects who volunteered for the experiment were all graduate students. A VR-14 CRT display driven by a PDP-8/e computer presented the stimuli. The surface of the display was coated with an ultrashort persistence phosphor. The laboratory equipment and environment are described elsewhere (Mayzner, 1968, 1975).

The stimuli consisted of 36 letter Xs arrayed next to each other, forming a straight line across the middle of the display surface. Display luminance was measured at $1 \mathrm{~mL}$ and the subject was seated $2 \mathrm{ft}$ in front of the display screen. The $36 \mathrm{Xs}$ 
Table 1

Display Orderings

\begin{tabular}{cc}
\hline Ordering & Order of Presentation \\
\hline 3 & $1,4,7,10, \ldots, 31,34,2,4,8,11, \ldots, 32,35,3,6,9,12, \ldots, 33,36$ \\
6 & $1,7,13, \ldots, 31,2,8,14, \ldots, 32,3,9,15, \ldots, 33,4,10,16, \ldots, 34,5,11,17, \ldots, 35,6,12,18, \ldots, 36$ \\
12 & $1,13,25,2,14,26,3,15,27,4,16,28,5,17,29,6,18,30,7,19,31,8,20,32,9,21,33,10,22,34,11,23,35,12,24,36$ \\
18 & $1,19,2,20,3,21,4,22,5,23,6,24,7,25,8,26,9,27,10,28,11,29,12,30,13,31,14,32,15,33,16,34,17,35,18,36$ \\
\hline
\end{tabular}

Note-Ordering refers to the number of moving Xs.

were presented one at a time under four different orderings given in Table 1. These particular orderings were chosen because they promote dynamic visual movement with $3,6,12$, and 18 moving Xs, respectively. The individual presentation time (or on-time) of each letter was varied by the experimenter. The time between successive letter presentations (the off-time) was zero. Thus, the total display time for each trial was the individual letter on-time multiplied by 36 .

Before each session, the experimenter explained to each subject the four visual experiences of interest: (1) pure sequentiality, one $X$ at a time on the screen; (2) transient phase, more than one $X$ at a time but no smooth motion; (3) dynamic visual movement, $3,6,12$, or $18 \mathrm{Xs}$ in smooth motion across the screen; and (4) simultaneity, all $36 \mathrm{Xs}$ appearing at one time.

The on-times were changed and the subject was asked to indicate when his subjective experience was altered. The experimenter recorded the on-time for the first occurrence of each phase. On-times were changed in two different ways: (1) "down" direction, beginning with an obviously pure sequential display in which each letter's on-time is $500 \mathrm{msec}$, reduce the on-times successively until $1 \mathrm{msec}$; and (2) "up" direction, beginning with $1 \mathrm{msec} / \mathrm{letter}$, increase the on-times until the subject indicates pure sequentiality has been reached.

\section{RESULTS}

Table 2 gives the mean value of the individual letter on-times at which each threshold was reached. The results are given for the different orderings and two directions.

Threshold B is of special importance because it gives the upper temporal bound for dynamic visual

Table 2

Mean Values Over All Subjects for On-Time (in Milliseconds) of Each $X$ at Three Thresholds

\begin{tabular}{ccrrr}
\hline & & \multicolumn{2}{c}{ Direction } & \\
\cline { 3 - 4 } Ordering & Threshold & Down & Up & Average* \\
\hline \multirow{2}{*}{3} & A & 160.67 & 169.33 & 165.00 \\
& $\mathrm{~B}$ & 88.33 & 104.67 & 96.50 \\
& $\mathrm{C}$ & 2.93 & 5.67 & 4.30 \\
& $\mathrm{~A}$ & 128.67 & 134.00 & 131.34 \\
6 & $\mathrm{~B}$ & 36.00 & 51.83 & 43.92 \\
& $\mathrm{C}$ & 1.93 & 3.60 & 2.77 \\
& $\mathrm{~A}$ & 133.33 & 132.67 & 133.00 \\
12 & $\mathrm{~B}$ & 16.67 & 24.17 & 20.42 \\
& $\mathrm{C}$ & 1.33 & 4.57 & 2.95 \\
& $\mathrm{~A}$ & 126.66 & 111.33 & 119.00 \\
18 & $\mathrm{~B}$ & 11.50 & 17.33 & 14.42 \\
& $\mathrm{C}$ & 1.33 & 4.63 & 2.98 \\
\hline
\end{tabular}

*Average over both directions. movement. The values for B in the "up" direction are consistently higher than those for "down." For example, with six moving Xs, Threshold B appears as $51.83 \mathrm{msec}$ and $36.00 \mathrm{msec}$ for up and down, respectively. This result agrees with our expectation that the threshold should be viewed as an interval of time over which a change in perceptual organization occurs. Further, higher values for the up direction agree with the "intuition" that, as the times are increased (up direction), the subject experiences the smooth motion of dynamic visual movement. That perception is repeatedly reinforced so the subject will abandon it only at the last possible time.

With decreasing on-times, however, the subject passes through the transient phase. A shorter on-time will be required before the subject is willing to announce that the smooth dynamic visual movement has been attained for the first time.

As the number of Xs in motion increases, the time for Threshold B decreases. While the value is $96.50 \mathrm{msec}$ for 3 moving Xs, it decreases to $14.42 \mathrm{msec}$ for 18 moving Xs. We can consider an on-time in this range, say $80 \mathrm{msec}$, and suggest what may be an explanation for this decrease. At $80 \mathrm{msec}$ dynamic visual movement obtained for three Xs. Each $\mathrm{X}$ traverses a relatively long path very slowly. With $18 \mathrm{Xs}$, however, no such smooth motion is reported at $80 \mathrm{msec}$. The path (from Table 1) is only two Xs in length. New Xs are being posted on the screen with little opportunity to reinforce the motion of earlier Xs. With $18 \mathrm{Xs}$, smooth motion characteristic of dynamic visual movement is detectable only in a narrow range of presentation times.

\section{DISCUSSION}

In the first account of dynamic visual movement (Mayzner \& Tresselt, 1970), the interval of time between the presentation of adjacent Xs within a group was $35 \mathrm{msec}$. A recent study (Agresti \& Mayzner, 1978) suggests that this interval may be as high as $315 \mathrm{msec}$ and still promote the movement effect. To establish this time interval for the present experiment, recall the order of presentation from Table 1. With six moving Xs, for example, one temporal grouping is $1,7,13,19,25,31$, meaning that the leftmost $X$ was displayed first; then (after five other Xs) the $X$ in the second position was displayed. The interval between displaying the adjacent letters was five times the individual letter on-time. Both earlier studies cited above suggest that this interval is critical to the perception of dynamic visual movement.

Table 3 lists this time interval for the present experiment. 
Table 3

Time Interval (in Milliseconds) Between Presentation of Adjacent Xs Within a Group at Threshold B

\begin{tabular}{cccc}
\hline Ordering & $\begin{array}{c}\text { Intervening } \\
\text { Stimuli* }^{*}\end{array}$ & Threshold B** & $\begin{array}{c}\text { Time } \\
\text { Interval }\end{array}$ \\
\hline 3 & 2 & 96.50 & 193.00 \\
6 & 5 & 43.92 & 219.60 \\
12 & 11 & 20.42 & 224.62 \\
18 & 17 & 14.42 & 245.14 \\
\hline
\end{tabular}

*Number of stimuli temporally intervening.

**Threshold B average letter on-time in milliseconds.

The values, varying from 193 to $245 \mathrm{msec}$, are well within the range mentioned above. Perhaps the most appropriate way to express the upper limit of dynamic visual movement is to use this time interval and not the on-time alone.

A more general outcome of the experiment should not be slighted. The same display, differing only in individual presentation times of the stimuli, elicit reports of four different perceptual organizations by the subject. Furthermore, the changes in state occur at times that exhibit a pattern that suggests that there are highly regular and systematic processing mechanisms at work.

\section{REFERENCES}

Agresti, W. W., \& Mayzner, M. S. Robustness of the dynamic visual movement effect. Bulletin of the Psychonomic Society, $1978,12,147-148$.

MAYZNER, M. S. The research potential of a computer-based cathode-ray tube display system. Behavior Research Methods \& Instrumentation, 1968, 1, 41-43.

MAYZNER, M. S. Studies in visual information processing in man. In R. Solso (Ed.), Information processing and cognition. Hillsdale, N.J: Lawrence Erlbaum, 1975.

Mayzner, M. S., \& Tresselt, M. E. Visual dynamics of a novel apparent movement effect. Psychonomic Science, $1970,18,331-332$.

(Received for publication June 9, 1978.) 